\title{
RESPONSES OF THE FERTILITY, SEMEN QUALITY, BLOOD CONSTITUENTS, IMMUNITY AND ANTIOXIDANT STATUS OF RABBIT BUCKS TO TYPE AND MAGNETIZING OF WATER
}

\author{
Y.A. Attia ${ }^{1}$, A.E. Abd El-Hamid ${ }^{2}$, A.M. El-Hanoun ${ }^{3}$, M.A.Al-Harthi' ${ }^{1}$, G.M. Abdel-Rahman ${ }^{1}$, \\ M.M. Abdella ${ }^{3}$
}

${ }^{1}$ Arid Land Agriculture Department, Faculty of Meteorology, Environment and Arid Land Agriculture, King Abdulaziz University, P.O. Box 80208, Jeddah 21589, Saudi Arabia

${ }^{2}$ Animal and Poultry Production Department, Faculty of Agriculture, Damanhour University, Damanhour 22516, Egypt

${ }^{3}$ Animal Production Research Institute, Agriculture Research Center, Ministry of Agriculture, Egypt

Corresponding author: yaattia@kau.edu.sa

\begin{abstract}
This work aimed to test the responses of the fertility, semen quality, blood constituents, immunity and antioxidant status of rabbit bucks to water type (e.g., tap water and well water) and magnetizing of water exposed or unexposed to a magnetic field of $\approx 4000$ gauss. The experimental design was factorial 2 (type of water, e.g. tap vs. well water) $\times 2$ (magnetic treatments, e.g. unexposed vs. exposed to magnetic field) using forty mature $V$-line rabbit bucks randomly distributed to four groups of 10 animals each. The rabbit bucks were provided free access to the water and same diet. Well water had lower quality than tap water, i.e. higher $\mathrm{pH}$, conductivity, salinity, calcium, magnesium, and total hardness. Water magnetizing had less effect on tap water than on well water (e.g. on $\mathrm{pH}$, conductivity, salinity, calcium, magnesium, total hardness and dissolved oxygen). Bucks that consumed tap water showed better semen quality, metabolic profiles and immunity than those that drank well water. Magnetized water significantly increased body weight, feed intake, reaction time, fertility, sperm concentration, mass motility and total live sperm of bucks consuming well water and tap water. The improvements in fertility and semen quality concurred with significant increases in testosterone hormone, immunoglobulin A, antioxidant enzymes, and with decreases in lipid peroxidation biomarker malondialdehyde and thiobarbituric acid-reactive substances. In conclusion, well water induced a significant decrease in semen quality and hence fertility of males. Whereas magnetic treatment improved water quality, semen quality, blood picture and antioxidant status and hence buck fertility.
\end{abstract}

Key words: rabbit bucks, magnetic water, semen quality, physiological traits, immunity

Environmental factors had effects on productive and reproductive performance of farm animals and resulted in a decrease in semen quality and fertility of males (Mann and Lutwak-Mann, 1981; Rasooli et al., 2010; Attia et al., 2013; Gallo et 
al., 2014). Water quality is necessary for animal production as water is the fuel of life; it transports fluids and nutrients through the blood, maintains the integrity of cell structure, regulates body temperature (Bassuny et al., 2004; Chiba, 2009; Attia et al., 2013). The safe levels of substances found in drinking water have been documented by Vohra (1980). Excessive dietary mineral intake has been shown to increase excreta moisture and water intake (Johnson and Karunajeewa, 1985). Barton (1996) reported that animals drinking low quality water show lower productive performance. In addition, sodium deficiencies adversely affect utilization of dietary protein and energy and interfere with reproductive performance, whereas excessive sodium intake positively influences water consumption and induces wet dropping (Jacob et al., 2011; Attia et al., 2013).

In literature, the magnetic technology was investigated in the plant fields, but little attention was given to animal reproductive and production application (Coey and Cass, 2000; Al-Mufarrej et al., 2005). The principle of magnetic technology depends on a moving electric charge in the ion form and the magnetic field (Lin and Yotvat, 1989). In addition, magnetic technologies may be utilized as a substitute for chemical softening for improving water quality (Eisenberg et al., 1993). Contact of water with a permanent magnet for a considerable time produced magnetic charges and magnetic properties. Such magnetically treated water can decrease microbial load and improve the immune system (Kronenberg, 1985). Exposing of water to strong magnetic field affected minerals content of water and the effects depended on the strength of magnetic field and exposure time. Magnetizing of water can increase $\mathrm{pH}$ of water up to 9.2 and increase hydroxyl $(-\mathrm{OH})$ ions release to raise alkalinity (Lin and Yotvat, 1989; Tkachenko and Semyonova, 1995).

Nowadays, the use of magnets to improve water quality is of significant interest due to low cost compared to chemical and physical treatments. In this regard, exposing water to a magnetic field induces an elevation in calcium salts solubility; thus lime-scale depositing in pipes decreases (Sargolzehi et al., 2009; Zhao et al., 2002). A magnetic treatment changes mineral contents of water thus increasing their permeability through biological membranes (Lin and Yotvat, 1989; Goldsworthy et al., 1999). Mice that drank magnetized water had significantly increased sperm number, somniferous tubules diameter, and spermatogonium in testis (Zhao et al., 2002). Al-Daraji and Aziz (2008) reported that compared to cocks that drank unexposed water, those that drank water exposed to 2000 gauss had improved $(\mathrm{P} \leq 0.01)$ quality of semen and seminal plasma. Decreased dead spermatozoa, abnormal spermatozoa and acrosomal abnormalities and improved hatchability of Japanese quail eggs were reported by Tarasewicz et al. (2006). In addition, duration of the estrous cycle was increased due to exposure to electric magnetic field (Rodriguez et al., 2003).

This study aims to evaluate the responses of the fertility, semen quality, blood constituents, immunity and antioxidant status of rabbit bucks to type and magnetizing of water. 


\section{Material and methods}

Forty male V-line rabbits (an average of 7.5 months old) were randomly distributed among four homogeneous groups of 10 bucks each in factorial 2 (types of water $) \times 2$ (magnetic treatments) experimental design. The groups received the same diet and were subjected to the following treatments: tap water (TW) group, drinking tap water; well water (WW) group, drinking well water which were obtained from a desert well at Al-Ameria city, Alexandria governorate at a depth of $100 \mathrm{~m}$ (the analyses of water are shown in Table 1); magnetized tap water (MTW) group drinking tap water exposed to the magnetic field of approximately 4000 gauss; magnetized well water (MWW) group drinking well water subjected to the same treatment of MTW group.

Table 1. Analysis of water types used in the experiment

\begin{tabular}{|c|c|c|c|c|}
\hline \multirow{2}{*}{ Parameters } & \multicolumn{2}{|c|}{ Tap water } & \multicolumn{2}{|c|}{ Well water } \\
\hline & $(-)$ & $(+)$ & $(-)$ & $(+)$ \\
\hline $\mathrm{pH}$ & 6.83 & 7.10 & 7.51 & 8.13 \\
\hline Conductivity (ms/cm) & 693 & 736 & 1683 & 1809 \\
\hline Salinity $(\mathrm{mg} / \mathrm{l})$ & 360 & 390 & 1040 & 1060 \\
\hline Dissolved oxygen (ppm) & 6.5 & 7.3 & 6.4 & 6.9 \\
\hline Sodium $\left(\mathrm{Na}^{+}\right)(\mathrm{ppm})$ & 6.3 & 7.1 & 88.4 & 91.7 \\
\hline Total hardness (mg/l) & 436 & 452 & 828 & 737 \\
\hline Potassium $\left(\mathrm{K}^{+}\right)(\mathrm{ppm})$ & 1.4 & 1.8 & 24.2 & 27.9 \\
\hline Calcium $\left(\mathrm{Ca}^{2+}\right)(\mathrm{mg} / \mathrm{l})$ & 114.4 & 120.8 & 242.7 & 245.8 \\
\hline Magnesium $\left(\mathrm{Mg}^{2+}\right)(\mathrm{mg} / \mathrm{l})$ & 114.3 & 116.7 & 212.4 & 166.1 \\
\hline Chloride $\left(\mathrm{Cl}^{-}\right)(\mathrm{ppm})$ & 2.9 & 3.1 & 20.8 & 21.3 \\
\hline Carbonate $\left(\mathrm{CO}_{3}^{-}\right)(\mathrm{ppm})$ & 3.8 & 4.1 & 3.2 & 3.5 \\
\hline Bicarbonate $\left(\mathrm{HCO}_{3}^{-}\right)(\mathrm{ppm})$ & 24.1 & 25.6 & 25.5 & 26.1 \\
\hline Organic matter (ppm) & 50 & 41 & 44 & 38 \\
\hline
\end{tabular}

(-) Without magnetic exposure; (+) With magnetic exposure.

Water was exposed to a magnetic field by a permanent magnet in a compact form using a unit called Aqua Correct (Magnetic Water Softeners and Conditioners, Blue Goose Sales, 200 S Duane Ct, Post Falls ID 83854, USA). This is coaxial permanent system equipment that produced magnetic field strength as high as 4000 gauss. The function is pure magnetic physical so the crystal structure of lime scale will change and can easily be removed. The strength of the magnet was measured by a gauss meter before the initiation and after the termination of the experiment. This measurement and that for water composition were carried out at Application Laboratory, City for Scientific Research and Biotechnology, Japanese University, Egypt. The analyses of two water types are shown in Table 1.

The bucks were housed in a naturally ventilated building and kept in individual Italian wire galvanized cages $(60 \times 55 \times 40 \mathrm{~cm})$, equipped with manual feeders and automatic drinkers. Animals were fed pelleted rations and kept under similar management (environmental temperature, humidity, stocking density light-dark cycle 
and day length) and hygienic conditions (vaccination and health care). The lighting program provided 14:10 h light dark cycle per day. The experiment lasted for 28 weeks from October 2011 to May 2012. The average temperature and relative humidity during this period was $18^{\circ} \mathrm{C}\left(13^{\circ} \mathrm{C}\right.$ Min and $23^{\circ} \mathrm{C}$ Max $)$ and $71 \% \mathrm{RH}(65 \%$ Min and 75\% Max), respectively. Feed and fresh water were offered ad libitum.

A pelleted commercial rabbit diet $(0.62 \mathrm{~cm}$ in length, $0.45 \mathrm{~cm}$ in diameter) contained hay clover, wheat bran, maize, soybean meal, dicalcium phosphate, sodium chloride and vitamin and mineral premix was provided for bucks. The diet was fed without antibiotics and coccidiostats. Diet was analyzed using Association of Official Analytical Chemistry (2007) whereas neutral detergent fiber (NDF), acid detergent fiber (ADF) and hemicellulose were analyzed as cited by Attia et al. (2013). The nutrient profiles showed dry matter $(93.4 \%)$, crude protein $(17.4 \%)$, crude fiber $(14.1 \%)$, ether extract $(3.5 \%)$, nitrogen free extract $(51.3 \%)$, ash $(7.1 \%)$, NDF $(33.5 \%), \operatorname{ADF}(15.9 \%)$, hemicellulose $(17.6 \%)$, and the calculated digestible energy value according to NRC (1977) was $2464 \mathrm{kcal} / \mathrm{kg}$ diet. The experiment was approved by Animal Production Research Institute Scientific Council. The institutional ethics keep the right for animal welfare and prohibit animal stressful conditions.

Twenty-five samples of blood ( 5 samples $\times 5$ weeks) per treatment were collected from the ear vein of bucks and placed immediately on ice tank. The samples were collected from the same animals after they had been selected randomly. The blood was collected in tubes with or without heparin to collect plasma and serum, respectively. Blood plasma and serum were collected from blood by centrifugation at $860 \times \mathrm{g}$ for $20 \mathrm{~min}$ at $4^{\circ} \mathrm{C}$ and stored at $-60^{\circ} \mathrm{C}$ (Attia et al., 2009).

Semen collection occurred weekly over the 20 weeks after 8 weeks adaption period in which bucks were trained for semen collection and adapted to the experiment conditions according to IRRG (2005 a). Thus, 120 ejaculates were obtained during the experiment period as 30 ejaculates per treatment. Ejaculates were collected using an artificial vagina maintained at $45-46^{\circ} \mathrm{C}$ and a teaser doe.

Daily feed intake (g/buck/day) and body weight (g/buck) were recorded during the experimental period. The ejaculate volume for each buck was recorded after removal of the gel mass. Reaction time ( $\mathrm{sec}$ ), as an indication of libido, was the time interval from the introduction of the teaser doe into the male's cage to ejaculation. Immediately after collection, semen was kept at $35^{\circ} \mathrm{C}$ in a water bath in order to be evaluated.

Mass motility was determined using two drops of fresh semen, which were placed on a warmed slide and covered with a cover slip $(20 \times 20 \mathrm{~mm})$. Mass motility from at least three fields was examined at $37^{\circ} \mathrm{C}$ under a microscope with phase contrast optics, at $40 \times$ and assessed from 0 to $100 \%$. A weak eosin solution was used at a rate of 1:99 before counting the cells, for evaluation of sperm concentration $\left(\times 10^{6} / \mathrm{ml}\right)$ according to Smith and Mayer (1955) by the improved Neubauer haemocytometer slide (GmbH+Co., Brandstwiete 4, 2000 Hamburg 11, Germany). Total sperm output was calculated by multiplying semen ejaculate volume and semen concentration. Assessment of live spermatozoa and abnormal spermatozoa was performed using an eosin-nigrosine blue staining mixture (Blom, 1950). The percentage of live, dead and abnormal spermatozoa was determined by using stains that penetrate cells with dam- 
aged membranes. Normal live sperm was not stained by the eosin stain and appeared white in color, whereas dead sperm was stained by eosin and appeared pinkish in color due to loss of membrane integrity. Normal sperm had an oval head with a long tail. Abnormal sperm had a head, midpiece or tail defects, e.g. a large or misshapen head or a crooked or double tail.

Total live sperm was calculated by multiplying ejaculate volume by sperm concentration by livability percentage. Total normal sperm was calculated by multiplying ejaculate volume by sperm concentration by normal sperm percentage. Total functional sperm fraction (TFSF) was also calculated by multiplying total sperm output and sperm motility and normal morphology sperm (Correa and Zavos, 1996).

The reproductive rhythm was semi-intensive and does were resubmitted to natural mating 11 days after delivery (43-days inter-kindling interval) according to Attia et al. (2009). Bucks of each group were mated with 30 nulliparous female rabbits and fertility rate was recorded according to IRRG (2005 b). Mating was carried out in the morning; both does and bucks were selected randomly within the same group. Each doe was transferred to the buck's cage for mating and returned to its cage after copulation. Each doe was subjected to two services within 30 min by the same buck. The rabbit does that failed to become pregnant after three successive natural matings were discarded from the experiment. Pregnancy was diagnosed by abdominal palpation at day 10 after service. Fertility percentage was estimated for each buck per treatment as the number of pregnant does divided by the number of mated does $\times 100$.

Serum total protein, albumin, glucose, cholesterol, total lipid, urea, creatinine, urea to creatinine ratio, the activities of aspartate aminotransferase (AST) and alanine aminotransferase (ALT) were determined by colorimetric enzymatic methods using commercial kits purchased from Diamond Diagnostic company (23 EL-Montazah St. Heliopolis, Cairo, Egypt, http://www.diamonddiagnostics.com).

Total antioxidant capacity (TAC) was measured ( $\mathrm{n}=10$ samples per treatment) according to Erel (2004). The antioxidant enzymes such as glutathione S-transferase (GST) activity using nitrobenzylchloride as a substrate, glutathione (GSH), glutathione peroxidase (GPx) activity and superoxide dismutase activity (SOD) were determined according to Attia and Kamel (2012). Lipid peroxidation biomarkers such as malondialdehyde (MDA) and thiobarbituric acid-reactive substances (TBARS) were assayed in the blood plasma according to Tappel and Zalkin (1959) and Conti et al. (1990), respectively.

Testosterone concentration in plasma was measured according to Attia and Kamel (2012) using immunoassay commercial kits (Biosource-Europe S.A., Nivelles, Belgium). The sensitivity of testosterone assay of ten replicates $0 \mathrm{ng} / \mathrm{mL}$ of the testosterone standard is $0.08 \mathrm{ng} / \mathrm{mL}$. The coefficient of difference was $7.8-9.6 \%$ for the intra-assay using 10 replicates. The coefficient of variation ranged from $8.4-9.1 \%$ for the inter-assay using 10 separate runs.

Blood samples ( $\mathrm{n}=10$ samples per treatment) were diluted 200 times with physiological saline before counting white blood cell counts (WBCs) and its fractions (lymphocyte, neutrophils, monocytes, eosinophils and basophil percentages) were determined according to Attia et al. (2013). They were counted on an Ao bright line 
hemocytometer using a light microscope at 100x magnification after diluting the blood samples 20 times with a diluting fluid $(3 \mathrm{ml}$ acetic acid glacial $+97 \mathrm{ml}$ distilled water + some of Leishman stain).

Red blood cells (RBCs) were counted on an Ao bright line hemocytometer using a light microscope at 400x magnification. Hemoglobin was determined by the cyanomethemoglobin method as cited by Attia et al. (2013). Wintrobe hematocrit tubes were used for determination of the hematocrit value. Blood samples were centrifuged for 20 minutes at $4000 \mathrm{rpm}$, and then hematocrit values were measured by reading the packed cell volume $(\mathrm{PCV})$ on the graduated scale.

The mean volume $\left(\mathrm{MCV} ; \mu \mathrm{m}^{3}\right)=($ Hematocrit $(\%) / \mathrm{RBCs}) \times 10$.

The mean cell hemoglobin concentration $\left(\mathrm{MCH}, \mathrm{pg}=10^{-12}\right)=($ Hemoglobin concentration $(\mathrm{g} / \mathrm{dl}) / \mathrm{RBC}, \mathrm{s}) \times 10$.

The mean cell hemoglobin concentration $(\mathrm{MCHC}, \%)=(\mathrm{Hemoglobin}(\mathrm{g} / \mathrm{dl}) / \mathrm{He}-$ matocrit \%) $\times 100$ were calculated.

Humoral immune response was determined according to Prescott et al. (1982). Titers were measured as log values. Five bucks from each group received $0.5 \mathrm{ml}$ of $50 \%$ sheep red blood cells (SRBCs) via intramuscular injection as T-dependent antigen. Hemagglutination antibodies were assessed 7 days later by hemagglutination test. Lysozyme activity was determined according to Schultz (1987).

Different types of immunoglobulins (IgG, IgM and IgA) in blood serum were determined ( $\mathrm{n}=5$ samples per treatment) using commercial ELISA kits (Kamiya Biomedical Company, USA).

All data were subjected to analysis of variance using factorial design (2 types of water $\times 2$ magnetic treatments) of the general linear model using SAS software program (SAS, 2002) according to the following model:

$$
y_{i j k}=\mu+\alpha_{i} \beta_{j}+\alpha \beta_{i j}+e_{i j k}
$$

where:

$$
\begin{aligned}
& Y=\text { the dependent variable, } \\
& \mu=\text { general mean, } \\
& \alpha=\text { type of water effect, } \\
& \beta=\text { magnetic effect, } \\
& \alpha \beta=\text { interaction effect, } \\
& e=\text { random error. }
\end{aligned}
$$

Before analyses, all percentages were subjected to logarithmic transformation $(\log 10 x+1)$ to normalize data distribution. Correlation between TBARS and MDA was done using Pearson correlation. Mean difference at $\mathrm{P} \leq 0.05$ was tested using Student-Newman-Keuls test. Survival rate was analyzed as percentage using chisquare analyses. 


\section{Results}

Table 1 indicates the influence of quality of water and of magnetic field on water quality. The quality of water was different between TW and WW, with WW having poorer quality (conductivity, salinity, $\mathrm{Ca}, \mathrm{Mg}$, total hardness) compared to TW. Thus, the exposure of water to the magnetic field induced greater influence on WW than on TW. In addition, a considerable difference was shown in $\mathrm{Ca}$ and $\mathrm{Mg}$ contents of water between the two types of water with TW having favorable quality. However, we did not observe any health problems among different groups of animals and this was confirmed by the lack of mortality.

Table 2 displays the data for body weight, body weight gain, and feed intake. Bucks that drank WW had lower $(\mathrm{P} \leq 0.05)$ final body weight, body weight gain and feed intake $(\mathrm{P} \leq 0.05)$ compared to those drinking the TW. Final body weight, body weight gain and feed intake of bucks increased $(\mathrm{P} \leq 0.05)$ due to magnetic treatment of WW and TW compared with unexposed water.

Table 2. Effects of type of water and/or magnetic exposure on body weight parameters and feed intake of rabbit bucks

\begin{tabular}{|c|c|c|c|c|c|}
\hline \multirow{2}{*}{ Water type } & \multirow{2}{*}{ Treatment } & \multicolumn{3}{|c|}{ Body weight $(\mathrm{g})$ at } & \multirow{2}{*}{$\begin{array}{l}\text { Feed intake } \\
\text { (g/buck/day) }\end{array}$} \\
\hline & & initial & final & gain & \\
\hline \multicolumn{6}{|c|}{ Interaction effect } \\
\hline \multirow[t]{2}{*}{ tap water } & $(-)$ & 3705 & $4269 \mathrm{~b}$ & $564 \mathrm{~b}$ & 247 \\
\hline & $(+)$ & 3735 & $4428 \mathrm{a}$ & $693 \mathrm{a}$ & 263 \\
\hline \multirow[t]{2}{*}{ well water } & $(-)$ & 3751 & $4073 \mathrm{c}$ & $322 \mathrm{c}$ & 234 \\
\hline & $(+)$ & 3729 & $4325 \mathrm{ab}$ & $596 \mathrm{~b}$ & 251 \\
\hline \multicolumn{6}{|c|}{ Main effect of water type: } \\
\hline \multicolumn{2}{|c|}{ tap } & 3720 & 4348 a & $629 \mathrm{a}$ & $255 \mathrm{a}$ \\
\hline \multicolumn{2}{|l|}{ well } & 3740 & $4199 \mathrm{~b}$ & $459 \mathrm{~b}$ & $242 \mathrm{~b}$ \\
\hline \multicolumn{6}{|c|}{ Main effect of magnetic treatment: } \\
\hline \multicolumn{2}{|c|}{$(-)$} & 3728 & $4171 \mathrm{~b}$ & $443 \mathrm{~b}$ & $240 \mathrm{~b}$ \\
\hline \multicolumn{2}{|l|}{$(+)$} & 3732 & $4376 \mathrm{a}$ & $645 \mathrm{a}$ & $257 \mathrm{a}$ \\
\hline \multicolumn{2}{|l|}{ RSME } & 143 & 158 & 16.35 & 7.23 \\
\hline \multicolumn{6}{|l|}{ P value: } \\
\hline \multicolumn{2}{|l|}{ interaction } & 0.734 & 0.071 & 0.006 & 0.006 \\
\hline \multicolumn{2}{|l|}{ type of water } & 0.721 & 0.001 & 0.001 & 0.001 \\
\hline \multicolumn{2}{|c|}{ magnetic treatment } & 0.582 & 0.001 & 0.001 & 0.001 \\
\hline
\end{tabular}

$\mathrm{a}, \mathrm{b}, \mathrm{c}, \mathrm{d}-$ values with different superscript within columns are significantly different $(\mathrm{P} \leq 0.05)$. Unmagnetized exposure (-), magnetized water $(+)$.

Reaction time, fertility rate, sperm concentration, mass motility, and total live sperm were affected $(\mathrm{P} \leq 0.05)$ by water type and/or magnetic exposure (Table 3$)$. Tap water significantly improved reaction time, fertility, sperm concentration, mass motility, and total live sperm compared to WW. Also, magnetized water resulted in significantly improved reaction time, fertility, sperm concentration, mass motility, and total live sperm of bucks that consumed TW and WW compared to unexposed water. These parameters showed also significant type of water $\times$ magnetic exposure interaction, indicating that semen quality was improved due to magnetic treatments for both types of water and the response depends on type of water. 


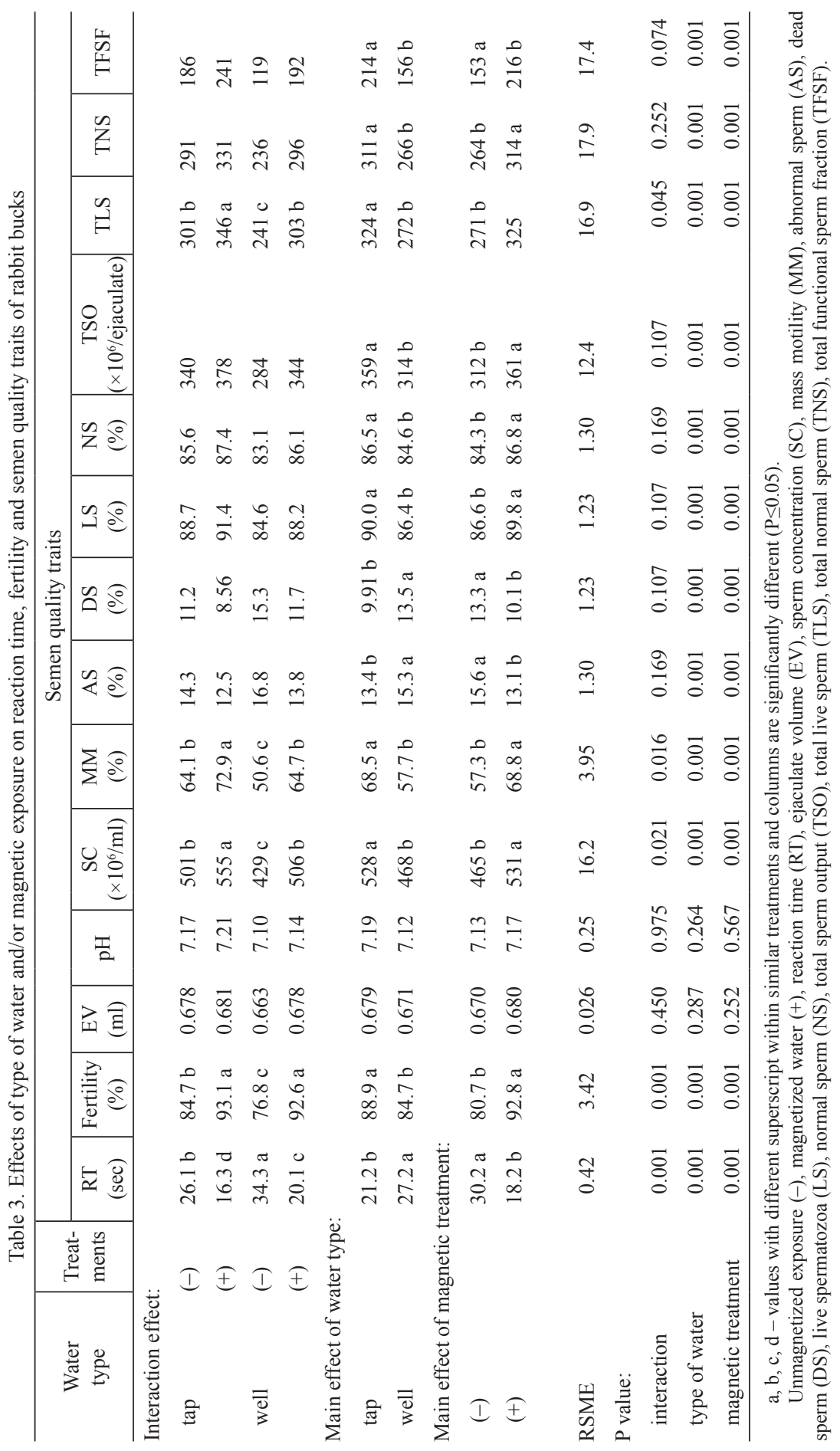




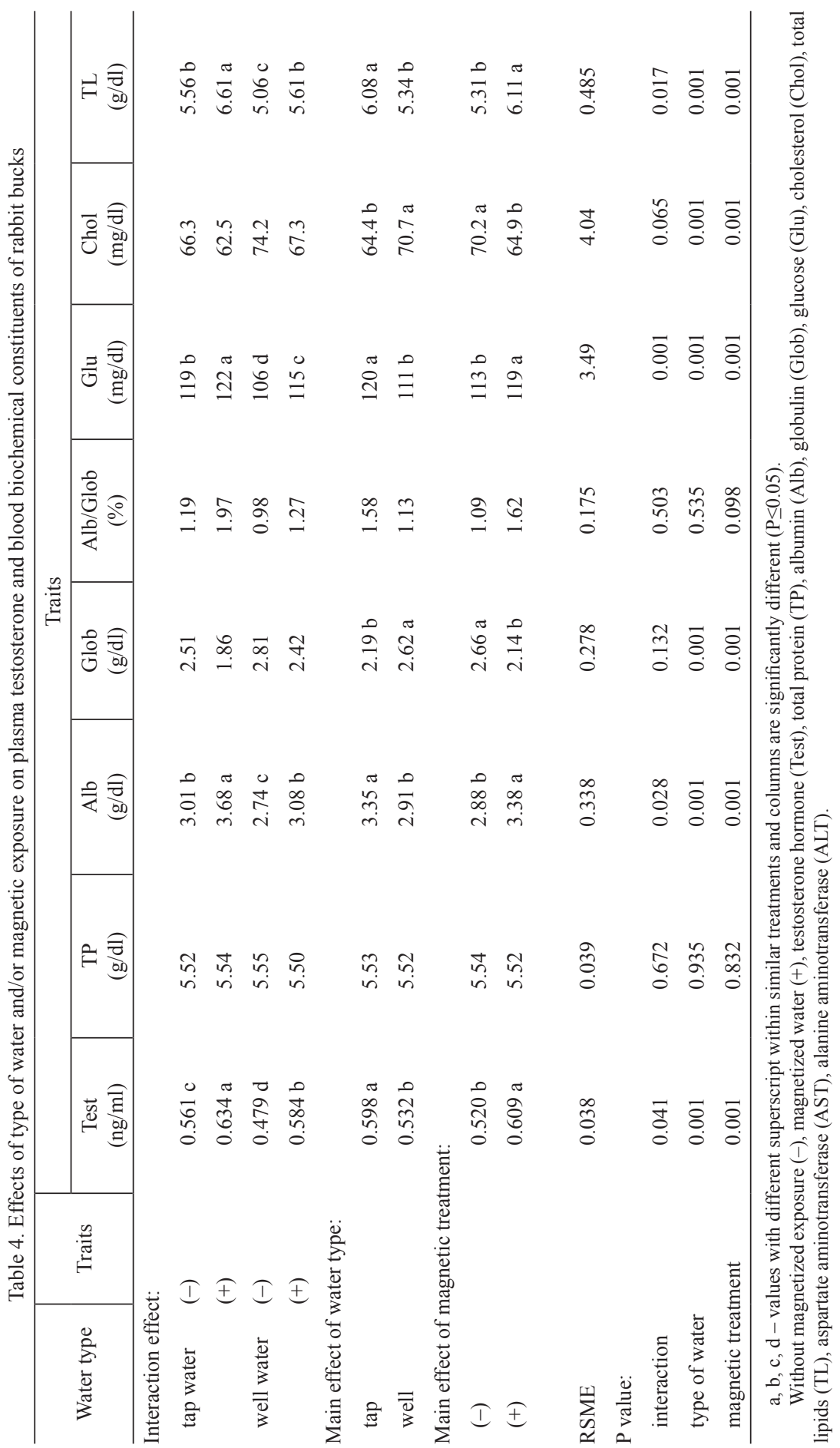




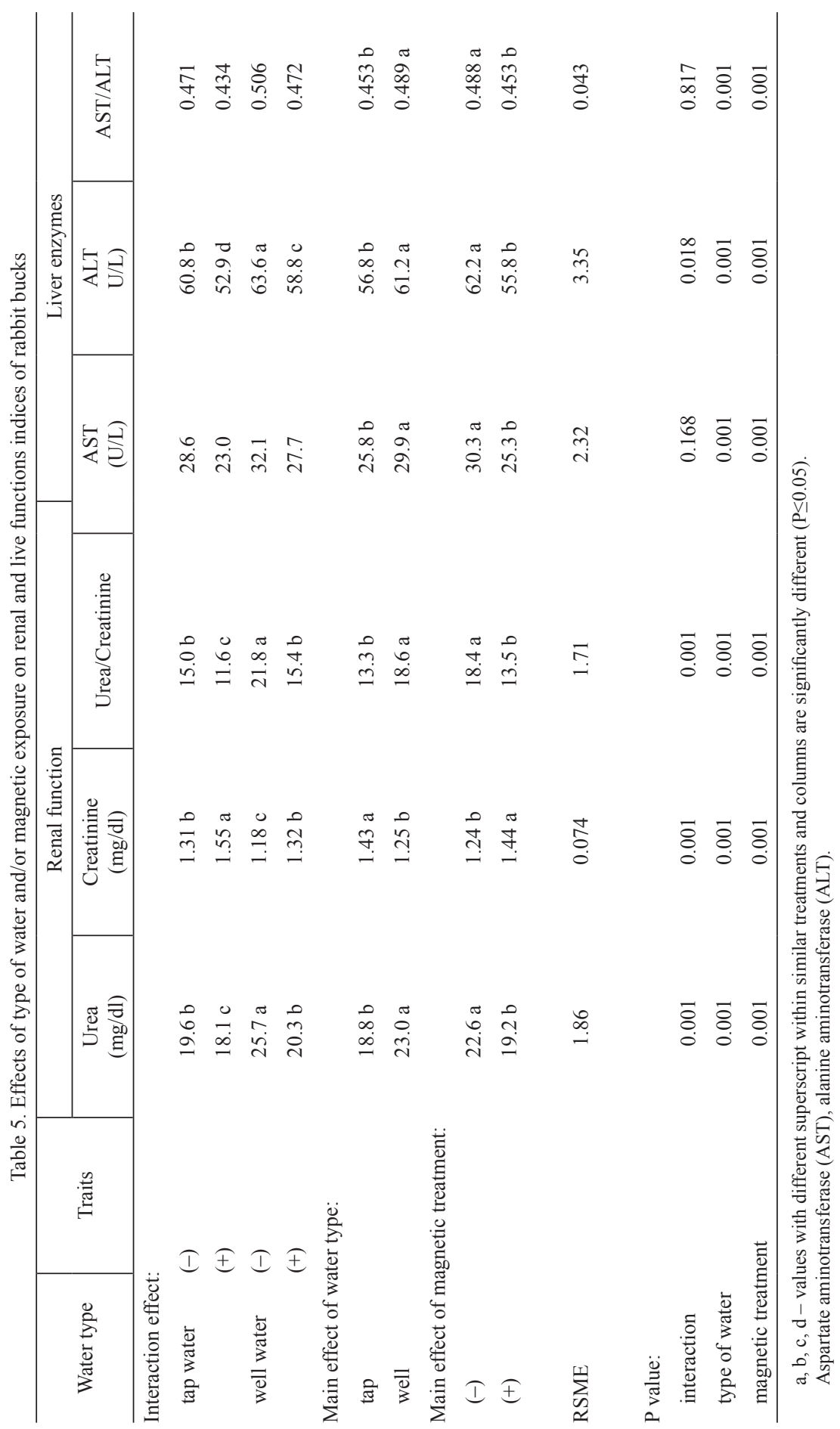




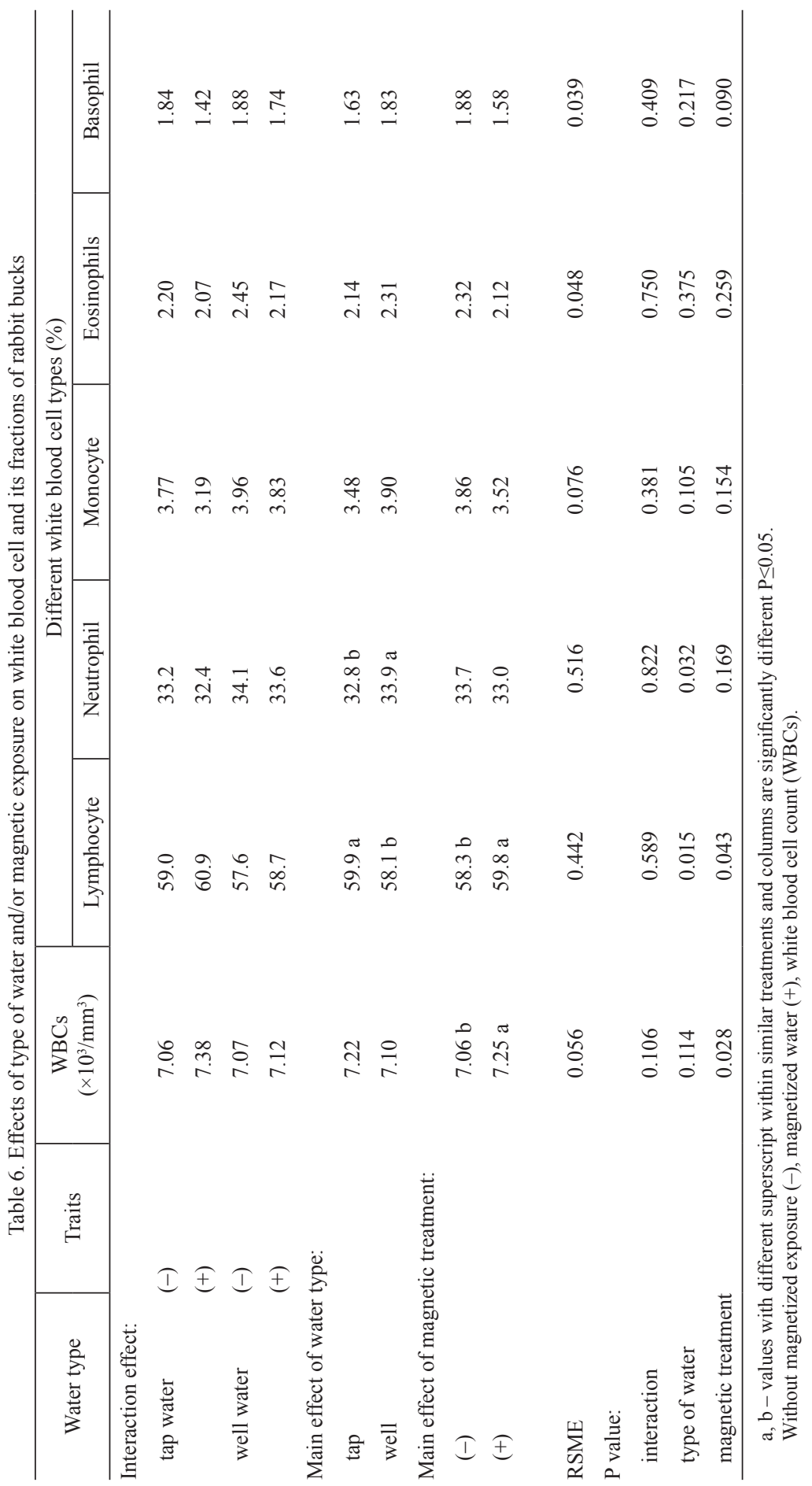




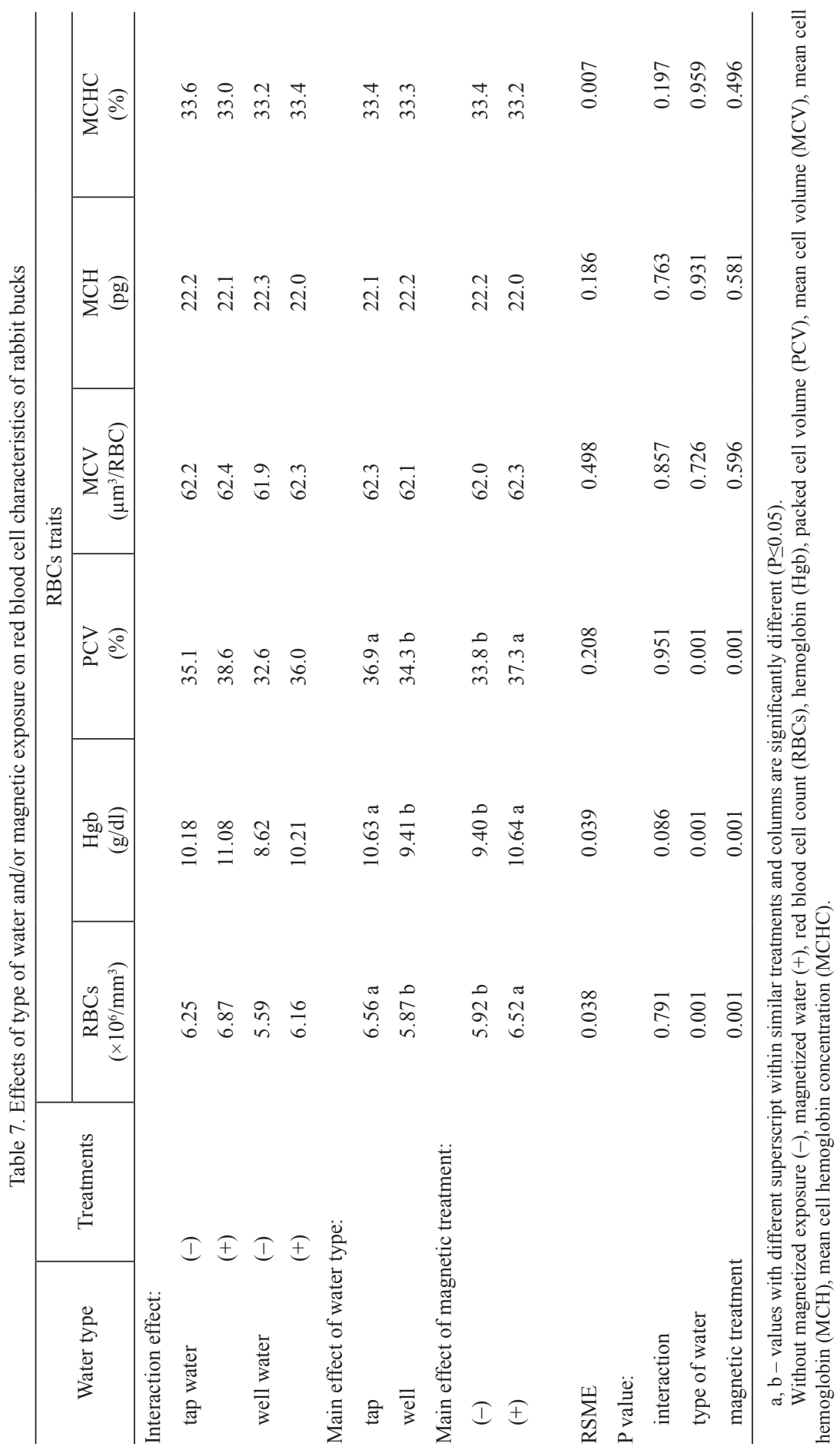




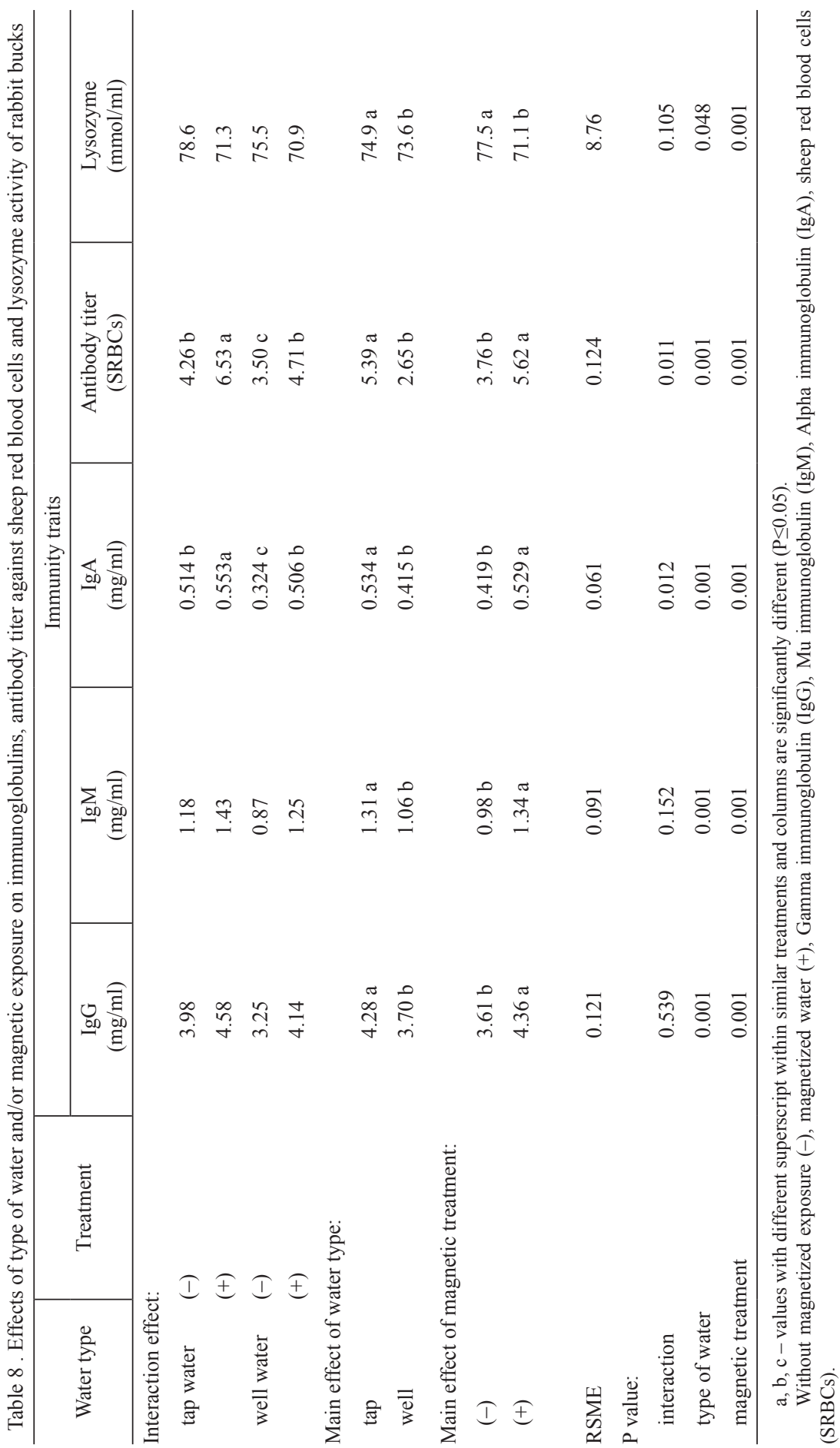




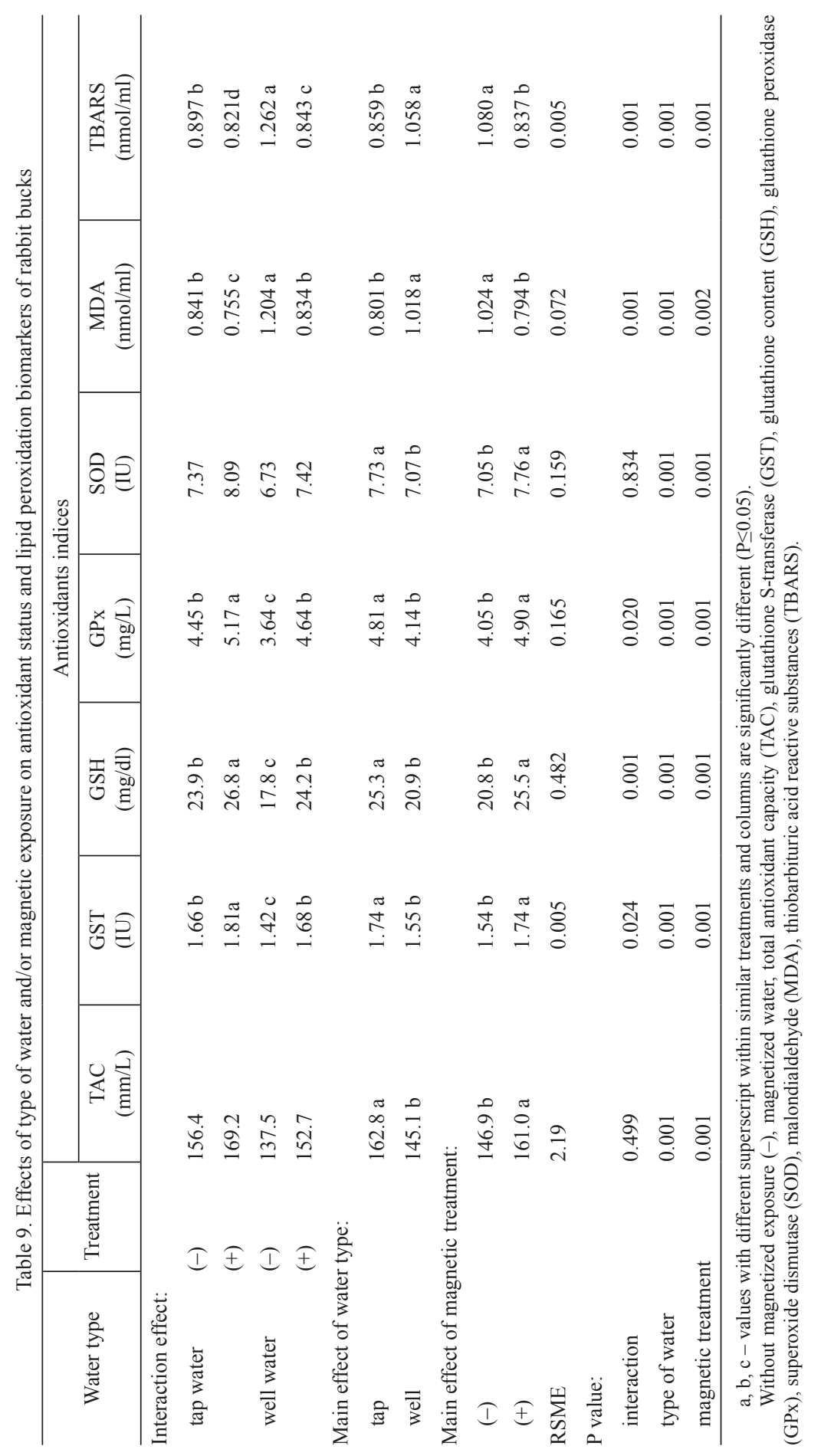


Other semen quality traits such as abnormal sperm, normal sperm, dead sperm, live sperm, total sperm output, total normal sperm and TFSF were significantly affected $(\mathrm{P} \leq 0.05)$ by type of water and magnetic exposure, but not by the interaction between both factors. The TW significantly increased $(\mathrm{P} \leq 0.05)$ normal sperm, live sperm, total sperm output, total normal sperm and TFSF compared to WW, but abnormal sperm and dead sperm decreased. However, water treatments did not affect ejaculate volume and semen $\mathrm{pH}$.

Table 4 shows the influence of various water treatments on plasma testosterone, blood biochemical contents. Plasma testosterone, serum albumin, plasma glucose and total lipid were significantly decreased $(\mathrm{P} \leq 0.05)$ in bucks that consumed WW compared to those on TW and also increased due to magnetic exposure of WW and TW. These parameters and plasma cholesterol showed also a significant type of water $\times$ magnetic exposure interaction. On the other hand, serum globulin and plasma cholesterol showed higher values in WW compared to TW. In addition, serum globulin and plasma cholesterol were significantly decreased in bucks that consumed magnetized compared to unmagnetized water, but only serum globulin was not influenced by the interaction between water type and magnetic treatment. Furthermore, water treatments did not influence albumin/globulin ratio.

There were significant effects of water type and magnetic exposure on serum urea, creatinine, urea/creatinine ratio and ALT (Table 5). Serum urea, urea/creatinine ratio and ALT were significantly higher $(\mathrm{P} \leq 0.05)$ in bucks that drank WW compared to those that drank TW, but serum creatinine was lower. In addition, water magnetizing significantly reduced serum urea, urea/creatinine ratio and ALT of bucks consuming TW and WW compared to unmagnetized water, but increased serum creatinine. These parameters showed also a significant type of water $\times$ magnetic exposure interaction, showing improved renal and liver function due to magnetic treatment.

Significant effects of water type and magnetic treatment were shown in serum AST and AST/ALT ratio, but the interaction between water type and magnetic exposure was not significant. Well water significantly increased $(\mathrm{P} \leq 0.05)$ serum AST and AST/ALT ratio while water magnetizing resulted in a significant decrease of AST and AST/ALT ratio.

Table 6 presents the impact of water treatments on white blood cells count and different white blood cell types. There were no effects $(\mathrm{P} \geq 0.05)$ of water type, magnetic treatment and the interaction between them on monocytes, eosinophils and basophils. There were significant effects of water type on lymphocytes and neutrophils. The results showed that TW significantly increased lymphocytes compared to WW, but decreased neutrophils. Magnetized water resulted also in significantly higher $(\mathrm{P} \leq 0.05) \mathrm{WBC}$ and lymphocytes. White blood cell count, lymphocytes and neutrophils showed no significant type of water $\times$ magnetic exposure interaction.

Table 7 indicates the effect of water treatments on RBC characteristics. There were significant effects of water type and magnetic treatment on $\mathrm{RBC}, \mathrm{Hgb}$, and PCV. It was found that TW significantly increased RBC, Hgb and PCV compared to those in bucks that drank WW. Magnetized water resulted also in significantly higher $(\mathrm{P} \leq 0.05) \mathrm{RBC}, \mathrm{Hgb}$ and $\mathrm{PCV}$ compared to those in bucks that drank unmagnetized water. All RBCs characteristics were not significantly affected by the interaction 
between type of water and magnetic exposure though the effect approached significance for $\mathrm{Hgb}(\mathrm{P} \leq 0.086)$, showing greater $\mathrm{Hgb}$ for magnetic treated water compared to unexposed water.

Table 8 demonstrates the influence of water treatments on immune indices. There were significant impacts of water type and magnetic treatment on $\operatorname{IgG}, \operatorname{IgM}$ and lysozyme. The results showed that TW significantly increased IgG, IgM, and lysozyme compared to those of bucks that drank WW. Magnetized water resulted also in significantly higher $(\mathrm{P} \leq 0.05) \mathrm{IgG}$ and $\operatorname{IgM}$ compared to those of bucks that drank unmagnetized water, but decreased lysozyme. In addition, there was a significant impact of water type, magnetic exposure and the interaction between them on IgA and antibody response to SRBCs. It was observed that TW resulted in significantly higher IgA and antibody to SRBCs compared to WW. Also, magnetized water significantly increased IgA and antibody to SRBCs of bucks consuming TW and WW.

Table 9 displays the influence of water treatments on antioxidant status. There were significant effects of water type or magnetic treatment on TAC, GST, GSH, GPx, SOD, MDA and TBARS. The results indicated that TW significantly increased TAC, GST, GSH, GPx and SOD compared to those of bucks that drank WW, but MDA and TBARS decreased. Magnetized water resulted also in higher $(\mathrm{P} \leq 0.05)$ TAC, GST, GSH, GPx and SOD compared to those of bucks that drank unmagnetized water, but MDA and TBARS decreased. Also, there was a significant interaction between them on antioxidant enzymes e.g., GST, GSH, GPx, lipid peroxidation biomarker such as MDA and TBARS. Obviously, magnetized water significantly increased GST, GSH, GPx of bucks that consumed TW and WW while decreasing MAD and TBARS. It should be mentioned that lipid peroxidation biomarkers MDA and TBARS were highly correlated $(\mathrm{P}=0.001 ; \mathrm{r}=0.96)$.

\section{Discussion}

The aim of this work was to investigate the impact of magnetic exposure on improving the productive and reproductive capability of buck rabbits exposed to environmental stress as manifested by consuming well water. The experimental hypothesis was validated by the poor quality of well water and performance of bucks on WW compared to those of bucks consuming TW. In addition, the magnetic treatments induced different responses depending on the TW vs. WW, e.g. $\mathrm{pH}$ (4.0 vs. $8.3 \%$ ), conductivity (6.2 vs. $7.5 \%$ ), salinity (8.3 vs. $1.9 \%), \mathrm{Ca}(5.6$ vs. $1.3 \%), \mathrm{Mg}$ $(2.1$ vs. $-21.8 \%)$, total hardness (3.7 vs. $-11.0 \%)$ and dissolved oxygen (12.3 vs. $7.8 \%$ ). This indicated that WW exhibited stronger response to the magnetic field than did the TW. The increase of salinity due to the magnetic exposure could be attributed to increasing soluble salts which concurred with the conductivity, while increasing dissolved oxygen could be due to the increase in organic matter from sewage or due to inorganic fertilizers such as phosphates and nitrate that can stimulate algae growth. It was reported that magnetic field made the water finer and with a consistent structure (Tkachenko and Semyonova, 1995; Coey and Cass, 2000). The increased 
fluidity, dissolved minerals and vitamins (Kronenberg, 1985) and thus biological activity of solutions resulted in increased performance of animals (Goldsworthy et al., 1999; Al-Mufarrej et al., 2005).

Body weight gain of rabbits, feed intake and hence feed utilization were impaired in rabbit bucks on WW compared to those on TW and the decrease in weight gains and feed intake amounted to 27.1 and $5.1 \%$, respectively. Thus, the decrease in feed intake could account for $18.8 \%$ of the decrease in weight gain while the majority of the impairment in weight gain $(81.2 \%)$ could be attributed to poor feed utilization.

Fertility, semen quality, blood biochemical and hematological traits, liver and renal functions, immune indices, cell mediated and humoral immunity, antioxidant enzymes were decreased in bucks that consumed WW, but MDA and TBARS increased compared with those of bucks on the TW. This indicates the negative effect of poor water quality on animal performance and welfare. Semen quality falls in the physiological range reported in literature (Nizza et al., 2003). Poor water quality negatively affected animal performance and welfare (Bassuny et al., 2004; Jacob et al., 2011; Attia et al., 2013).

Magnetic exposure increased weight gain (22.9 and 85.1\%) and feed intake (6.5 and $7.3 \%$ ), improved reaction time (37.5 vs. $40.9 \%)$, fertility rate (10 vs. $20.9 \%)$, sperm concentration (10.6 vs. $18.2 \%$ ), mass motility (13.7 vs. $28.1 \%$ ), total sperm output (11.5 vs. $20.7 \%$ ), total live sperm (14.9 vs. $26.1 \%)$, total normal sperm (13.4 vs. $25.4 \%$ ) and TFSF (29.4 vs. $60 \%$ ) of animals drinking TW and WW, meaning greater effect on WW. These are showing the positive impact of magnetic exposure on weight gain, feed utilization and reproductive traits of rabbit bucks. Similar results were reported by Rodriguez et al. (2003). The increase in testosterone due to magnetized water may have led to increased sexual desire as demonstrated by the decrease in the reaction time and the increase in fertility and semen quality (Tamer et al., 2005). In addition, the mass motility and fertility of rabbit bucks were significantly correlated (Attia and Kamel, 2012).

An increase in lymphocyte, RBCs and Hgb also concurred with improved semen quality, showing an improvement in the health status of bucks on magnetized water. These improvements along with those shown in metabolic profiles, testosterone hormone, immunity, antioxidant enzymes, liver and renal functions, and the decrease in lipid peroxidation biomarkers MDA and TBARS, may elucidate the enhancement in quality of semen and thus fertility of bucks. The increase in cellular and humeral immunity are further supporting evidences, showing that the liver was capable of synthesizing enough globulins for immunity (Fortun-Lamothe and Drouet-Viard, 2002). Similar results were reported by Tarasewicz et al. (2006), Attia and Kamel (2012) and Attia et al. (2013).

The improvements in metabolic profiles of rabbit bucks that drank magnetic exposed water could be attributed to enhancing metabolic cycles, minerals solubility such as $\mathrm{Fe}$ and/or $\mathrm{Cu}$ as evidenced by increasing RBCs and $\mathrm{Hgb}$ and nutrients transfer to various body cells, movement of blood within the arteries facilitating the transport of oxygen-bearing blood and nutrients to different body cells (Eisenberg et al., 1993; El-Kholy et al., 2008; Al-Daraji and Aziz, 2008). Moreover, magnetic treatment improved water quality, reduced lime deposition and bacterial load in 
pipes (Sargolzehi et al., 2009) favoring increasing aragonite/calcite ratio in the deposit (Coey and Cass, 2000). The decrease in lysozyme activity observed herein for magnetic water groups may indicate better immunity of bucks consuming magnetic exposed water. Lysozyme is a member of the innate humoral immunity that comes from the body and exhibits an increase in response to infection or tissue injury (Weir, 1983). Lysozyme was found to protect the body against bacterial, viral and inflammatory diseases (Sugahara et al., 2000). In addition, serum lysozyme levels were used as a biomarker for diagnosis of diseases, e.g. different types of leukemias (Osserman, 1973) as well as sarcoidosis (Canfield et al., 1974).

The increase in semen quality and the decrease in percentage of dead and abnormal sperm of bucks that consumed magnetized water could be attributed to the positive impact of magnetic water on antioxidant enzymes, lipid peroxidation biomarkers and immunity which improve body tolerance to pollutants and protect the body from the harmful effects of free radicals (Rommerts, 1990). The decrease in TBARS and MDA concentration in the magnetized water, can provide further evidences for the increase in semen quality/fertility and the improvement in the liver and renal functions as reflected in the improvements in the immunity and general health status of animals. Concentration of unsaturated fatty acids in the sperm cell is a limiting factor for sperm movement, cold resistance, viability and fertilization. Therefore, high unsaturated-fatty acids contents in the sperm cell require an effective antioxidant system to protect sperms from damage caused by peroxides formation and their negative impact on the sperm function (Roldan and Harrison, 1993; Attia and Kamel, 2012). In fact, vertebrate sperm show high metabolic activity rates and are rich in polyunsaturated fatty acids (Castellini et al., 2006), subjecting them to ROS induced oxidation. Lipid peroxidation is one of the major reactions leading to phospholipid loss, membrane injury, and a decrease in spermatozoa motility in mammals (Mann and Lutwak-Mann, 1981). The GPx enzyme occupies a particularly crucial role in the antioxidant protection of the cell by altering hydrogen peroxides into less destructive components (Olafsdottir and Reed, 1988). The increase in antioxidant status in blood plasma (GSH, GPx. SOD and GST) and the decrease in TBARS and MDA, suggested increasing stability of cell. However, TBARS showed higher values than MDA which could be explained by lack of specificity of the TBA reaction (Conti et al., 1990).

Magnetic treatment did not affect animal performance in several studies; for example, Patterson and Chestnutt (1994) observed that magnetic water did not exert a significant effect on performance and meat quality of lambs. In addition, Sargolzehi et al. (2009) reported that blood glucose, urea, $\mathrm{Na}, \mathrm{K}, \mathrm{Mg}$ and $\mathrm{P}$, fat, protein, lactose, solids not fat and total solids of goat milk were not affected by magnetic treatments. This contradiction in response to magnetic treatment could be attributed to water type and amount of hardness and strength of magnetic field, suggesting further research.

\section{Conclusions}

Poor water quality induced a significant decrease in semen quality and hence fertility of males. Whereas magnetic treatment resulted in improved water quality, 
semen quality, blood picture and antioxidant status and hence buck fertility. This may be intriguing in areas with limited water supply when well water is the main source for drinking.

\section{References}

A 1 - D a raji H.J., A ziz A.A. (2008). The use of magnetically treated water for improving semen traits of roosters. Al-Anbar J. Vet. Sci., 1: 79-92.

A 1- Mufarrej S., A l-B atshan H.A., Shalaby M.I., Shafey T.M. (2005). The effects of magnetically treated water on the performance and immune system of broiler chickens. Int. J. Poult. Sci., 4: 96-102.

Association Official Analytical Chemistry (2007). Official Methods of Analysis. 19th ed. Assoc. Off. Anal. Chem. Washington, DC, USA.

A t t i a Y.A., K a m e 1 K.I. (2012). Semen quality, testosterone, seminal plasma biochemical and antioxidant profiles of rabbit bucks fed diets supplemented with different concentrations of soybean lecithin. Animal, 6: 824-833.

A t ti a Y.A., Abd El-Hamid A.E., B over a F., El-S ay ed M.I. (2009). Reproductive and productive performance of rabbit does submitted to an oral glucose supplementation. Animal, 3 : 1401-1407.

A t t i a Y.A., A b d E 1 - Ha mid E.A., I s ma ie 1 A.M., E 1 N a g a r A., A s m a S. (2013). The detoxication of nitrate by two antioxidants or a probiotic and the effects on blood and seminal plasma profiles and reproductive function of NZW rabbit bucks. Animal, 7: 591-601.

B a r t o n T.L. (1996). Relevance of water quality to broiler and turkey performance. Poultry Sci., 75, $854-856$.

B a s s u n y S.M., S h e h a t a S.A., B a h g a t L.B., M o h a m e d S.I.A. (2004). Nitrate toxicity in rabbits, 1- Effect of nitrate in drinking water on digestion, some blood constituents and growth performance of growing rabbits. Egypt. J. Rab. Sci., 14: 147-158.

B 1 o m E. (1950). A one-minute live-dead sperm stain by means of eosin-nigrosin. Fertil Steril, 1: $176-177$.

Canfield R.E., Collins J.C., Sobel J.H. (1974). Human leukemia lysozyme. In: Osserman E.F., Canfield R.E., Beychok S. (Eds), Lysozyme. Academic Press, New York.

Castellini C., Cardinali R., Dal B o s co A., Minelli A., Camici O. (2006). Lipid composition of the main fractions of rabbit semen. Theriogenology, 65: 703-712.

Ch ib a L.I. (2009). Animal Nutrition Handbook. Second revision. http://umkcarnivores3.files.wordpress.com/2012/02/animal-nutrition2.pdf. Downloaded August 20, 2013.

C o e y J.M.D., C a s s S. (2000). Magnetic water treatment. J. Magn. Magn. Mater., 209: 71-74.

Conti M., Morand P.C., Levilla in P., Le monnier A. (1990). Methode simple et rapide de dosage du malondialdehyde. Act Pharm. Biol. Clin., 5: 365-368.

C orre a J.R., Z a v o s P.M. (1996). Preparation and recovery of frozen thawed bovine spermatozoa via various sperm selection techniques employed in assisted reproductive technologies. Theriogenology, 46: 1225-1232.

E i s e n b e rg D.M., Ke s s le r R.C., N or to ck F.E., C a 11 in s D.R. D e 1 b a n c o T.L. (1993). Unconventional medicine in the United States. Prevalence, costs, and patterns of use. New England. J. Med., 328: 246-252.

E 1-Kholy K.H., Sle em T.S.T., E 1- A a s s a r T.A., A bdelharith Hanaa (2008). Effect of dietary addition of Arak (Salvadora persica) on growth and reproductive performance in Black Baladi rabbit males. World Rab. Sci., 16: 21-27

Er e l O.A. (2004). Novel automated direct measurement method for total antioxidant capacity using a new generation, more stable ABTS radical cation. Clin. Biochem., 37: 277-285.

F ortun - L a m ot he L., D r o u e t - Vi ard F. (2002). Review: II - Diet and immunity: current state of knowledge and research prospects for the rabbit. World Rab. Sci., 10: 25-39.

Gallo A., Giuberti G., Masoero F., Palmonari A., Fiorentini L., Moschini M. 
(2014). Response on yield and nutritive value of two commercial maize hybrids as a consequence of a water irrigation reduction. Ita. J. Anim. Sci., 13: 594-599.

Goldsw or thy A., Wh itney H., Morris E. (1999). Biological effects of physically conditioned water. Water Res., 33: 1618-1626.

International Rabbit Reproduction Group IRRG. (2005 a). Guidelines for the handling of rabbit bucks and semen. World Rab. Sci., 13: 71-91.

International Rabbit Reproduction Group IRRG. (2005 b). Recommendations and guidelines for applied reproduction trials with rabbit does. World Rabbit Sci., 13: 147-164.

J a c o b J., P e s c a t or e T., C a n t or A. (2011). Why have my hens stopped laying! Bulletin. University of Kentuckys. College of Agriculture. USA. http://afspoultry.ca.uky.edu/files/pubs/Why_have my_hens_stopped_laying_eggs.pdf

Johns on R.J., Karunaje ew a H. (1985). The effects of dietary minerals and electrolytes on the growth and physiology of the young chick. J. Nutr., 115: 1680-1690.

Kronenberg K.J. (1985). Experimental evidence for effects of magnetic fields on moving water. IEEE Transaction on Magnetics, 21: 2059-2061.

L in I., Yotvat J. (1989). Exposure of irrigation water to magnetic field with controlled power and direction: effects on grapefruit. Alon Hanotea, 43: 669-674.

Ma n n T., L u tw a k - M a n n C. (1981). Male reproductive function and semen. Springer-Verlag, Berlin, Germany.

Nizza A., Di Me o C., Tarant o S. (2003). Effect of collection rhythms and season on rabbit semen production. Reprod. Domest. Anim., 38: 436-439.

O lafs d ottir K., Reed D.J. (1988). Retention of oxidized glutathione by isolated rat liver mitochondria during hydroperoxide treatment. Biochim. Biophys. Acta, 964: 377-382.

O s s e r m a n E.F. (1973). Monocytic and monomyelocytic leukemia with increased serum and urine lysozyme as a late complication in plasma cell myeloma. Br. Med. J., 8: 215-222

P a t t e r s o n D.C., C h e s t n u t t D.M.B. (1994). The effect of magnetic treatment of drinking water on growth, feed utilisation and carcass composition of lambs. Anim. Feed Sci. Tech., 46: 11-21.

Pres c ot t C.V., Wilk i e B.N., Hunter B., Juli a n R.J. (1982). Influence of purified grade pentachlorphenol on the immune response of chickens. Am. J. Vet. Res., 43: 481-487.

R a s o oli A., J a la li M.T., N ouri M., M oh a m m a di a n B., B a r a t i F. (2010). Effects of chronic heat stress on testicular structures, serum testosterone and cortisol concentrations in developing lambs. Anim. Reprod. Sci., 117: 55-59.

Rodriguez M., P et it c lerc D., B urchard J.F., Nguyen D.H., B lock E., D owney B.R. (2003). Responses of the estrous cycle in dairy cows exposed to electric and magnetic fields $(60 \mathrm{~Hz})$ during 8-h photoperiods. Anim. Reprod. Sci., 77: 11-20.

Roldan E.R.S., Harris on R.A.P. (1993). Diacylglycerol in the exocytosis of the mammalian sperms acrosome. Biochem. Soc. T., 21: 284-289.

R o m m e r t s F.F.G. (1990). Testosterone, an overview of biosynthesis, transport, metabolism, and action. In: Testosterone, action, deficiency and substitution, 1st ed., Nieschlag E., Behre H.M. (Eds). PP. 3, Springer-Verlag, Berlin, Germany.

Sargolzehi M.M., Rezaee Rokn-Abadi M., Naserian A.A. (2009). The effects of magnetic water on milk and blood components of lactating Saanen goats. Inter. J. Nutr. Metab., 1: 20-24.

S c hultz L.A. (1987). Methods in Clinical Chemistry. The C.V. Mosby Co. St Louis, pp. 742-746.

S m ith J.T., M a y e r D.T. (1955). Evaluation of sperm concentration by the hemacytometer method. Comparison of four counting fluids. Fertil Steril, 6: 271-275.

Sugahara T., Murakami F., Ya ma da Y., S a s a ki T. (2000). The mode of action of lysozyme as an immunoglobulin production stimulation factor. Biochim. Biophys. Acta, 1475: 27-34.

Tamer M.S., Grunew ald S., P a s ch U., Agrwal A., Glander H. (2005). Effects of magnetic-activated cell sorting on sperm motility and cryosurvival rates. Fertil Steril, 83, No. 5, May 2005, doi:10.1016/j.fertnstert.2004.11.052.

T a p p e 1 A.L., Z a 1 k in H. (1959). Inhibition of lipid peroxidation in mitochondria by vitamin E. Arch. Biochem. Biophoys., 80: 333-336.

Tarasewicz Z., Szczerbinska D., Majewska D., Danczak A., Ligocki M., Wols k a A. (2006). The effect of magnetic field on hatchability of Japanese quail eggs. Czech J. Anim. Sci., 51: 355-360. 
T k a chenko Y., S e m y o nova N. (1995). Your way to health, Magnetic water plus separate nutrition. In: Mysteries of Magnetic Energies. A Collection of Scientific Works on the Usage of Magnetic Energies in Medical Practice. Tkachenko Y.P. (Ed.), Printing Emirates, Printing \& Publishing-Sharjah, UAE. Part 6: pp, 225-244.

Vo h r a P.N. (1980). Water quality for poultry use. Feedstuffs, July 7.

We ir D.M. (1983). Immunology. An outline for students of medicine and biology. 5th ed. Churchill Livingstone, Edinburgh, London, Melbourne, New York, pp. 15-16.

Zha o J., Cu i X.U., M ing y u S.H.I. (2002). Effect of magnetized drinking-water on mouse testis. Chinese J. Lab. Anim. Sci., 12: 21-23.

Received: 10 VI 2014

Accepted: 4 XI 2014 